\title{
Assessment of Adjustments Methods in Traverse Networks for Positioning
}

\author{
Hart L. ${ }^{1 *}$, Basil D. D. ${ }^{2}$ and Oba T. ${ }^{3}$ \\ ${ }^{1,2,3}$ Department of Surveying and Geomatics, Faculty of Environmental Sciences, Rivers State University, Port \\ Harcourt, Nigeria \\ Corresponding Author: *lawrence.hart@ust.edu.ng; basildevote@gmail.com
}

https://doi.org/10.36263/nijest.2021.02.0283

\begin{abstract}
Various factors contribute to the degree of accuracy of the adjusted parameter (coordinate), one of which is the choice of adjustment model. Adjustment models seeks to eliminate (accounts) for the presence of random errors present in a given observations. The choice is critical for surveyors and other spatial analysts for optimal positioning and mapping projects since different adjustment models will yield different level of accuracy of spatial information generated irrespective of the quality of observations. For a traversing network, various adjustment models have been put forward which include; the Transit, the Bowditch, and the Crandels models. In spite of these models, internal consistency and reliability indicators of the network of positions are determined using the least squares adjustment model (observation equation and condition equation models). The aim of this work is to analyze the various traverse adjustment models. The approach deployed in this work was to compute the provisional coordinate of six traverse stations using the approximate methods of adjustment i.e., Bowditch and transit methods of traverse adjustment models. In addition, the least square adjustment models were deployed to minimize the propagation of residuals of the obtained values. The adjusted distances and directions were then compared with the observed distances and directions to obtain the residuals. The coordinate of positions was determined and the Root Mean Square Error (RMSE) associated with the traverse adjustment models are given as 0.128702264 and 0.008560954. Similarly, the RMSE of the adjusted values using the least square models are given as 0.007181432, and 0.005763969 for the observation and condition equation models respectively. The analysis of these results reveals that the traverse adjustment models are unique with capabilities embedded in the determination of the observables during data acquisition. However, for mapping and engineering survey of small locations, the transit method is more preferable to the Bowditch method.
\end{abstract}

Keywords: Adjustment models, Least squares adjustment, Traverse, Root Mean Square Error (RMSE)

\subsection{Introduction}

The determination of the precise position of point and survey line on the earth is critical for such purpose as topographic mapping, property boundary demarcation, engineering construction, environmental management and protection, navigations and fleet management, monitoring of dynamic changes on the earth crust. The process of determining the precise coordinate of a point on land, at sea, or in space with respect to an implied coordinate system is referred to as positioning (Vanicek and Krakiwsky, 1986), which is the basic role of the geomatics professionals (FIG 2004 as in Fajimirokun, 2012). Positioning can either be carried out by the classical methods which include, the method of traversing, triangulation, trilateration, intersection, and resection (Ghilani and Wolf, 2016) or by space-based positioning techniques (El-Rabbany, 2002; Hofmann-Wellenhof et al., 2008; Fubara et al., 2014).

Precise traverse is the most common classical method of positioning to the geomatics professionals. A traverse consists of a series of straight lines connecting successive points whose lengths and direction has been determined from field observations. These field observations are subject to error as a result 
of imperfection of instruments, environmental factors and limitation of the operator's skills. Accordingly, there is the need to carry out adjustment of computed spatial information obtained from these field observations. The consequence of adjustment methods is to spread the residuals between the observations, so that the observations become consistent and create convergent network of lines that defines the geometry. Although the approximation methods of adjustment are inadequate in adjusting high precision survey networks involving traverse, trilateration and triangulation networks, they are still very attractive to land surveyors who specialize in property boundary establishment, engineering construction, mapping activities in conjunction with satellite imageries. Consequently, the geomatician and other practitioners is therefore faced with the difficulty of choosing the most appropriate traverse adjustment model out of several. The best adjustment model is said to yield the minimum variance estimate (Uotila 1967; Vanicek, 1980; Ghilani and Wolf, 2006; Ogundare 2019).

The process of adjustment accounts for any presence of random errors (not systematic errors) in observations and increases the precisions of final values computed for the unknown parameters. In view of the requirement for the precision and reliability of adjusted values of spatial data, the need to identify the most optimal traverse adjustment models has become very critical. Hence, the traverse coordinate obtained using these techniques provided better estimates for position of all traverse stations and the accuracy of the adjustment can be checked and statistically tested. This research therefore seeks to investigate comparatively the various adjustment models to determine their individual uniqueness, fitness, weakness and strength as it relate to the purpose of positioning.

The various adjustment models used by geomatics and allied professionals for the adjustment of traverse network which is principally the approximation method; the transit method, the Bowditch method and Crandel method. The least squares adjustment was used to determine the most probable values of the coordinates and associated reliability indicators (i.e. standard error) to serve as a baseline of comparison.

\subsection{Study Area}

The study area is within Rivers State University (RSU), Nkpolu-Oroworukwu, Port Harcourt, Rivers State. It is within the bounds of latitude $004^{\circ} 49^{\prime} 34^{\prime \prime} .66 \mathrm{~N}$ and $004^{\circ} 46^{\prime} 34^{\prime \prime} .66 \mathrm{~N}$ of the equator, longitude $006^{\circ} 57^{\prime} 25^{\prime \prime} \mathrm{E}$ and $006^{\circ} 58^{\prime} 38^{\prime} .30 \mathrm{E}$. It is bounded in the north and east by Diobu Area, in the south by Eagle Island and in the West by Rumeme Agip. The Study covers an approximate area of 60 hectares and is bounded by the following geodetic monument WSP003, SVG GPS 001 to SVG GPS 006; it covers the entire area of the Senate Building, the F and G block Hostel, the Faculty of Sciences, Engineering, Management and Environmental Sciences including the Post Graduate School as shown in the Figure 1. The sample field observations as obtained from the study area was subjected to the adjustment models discussed in this paper.

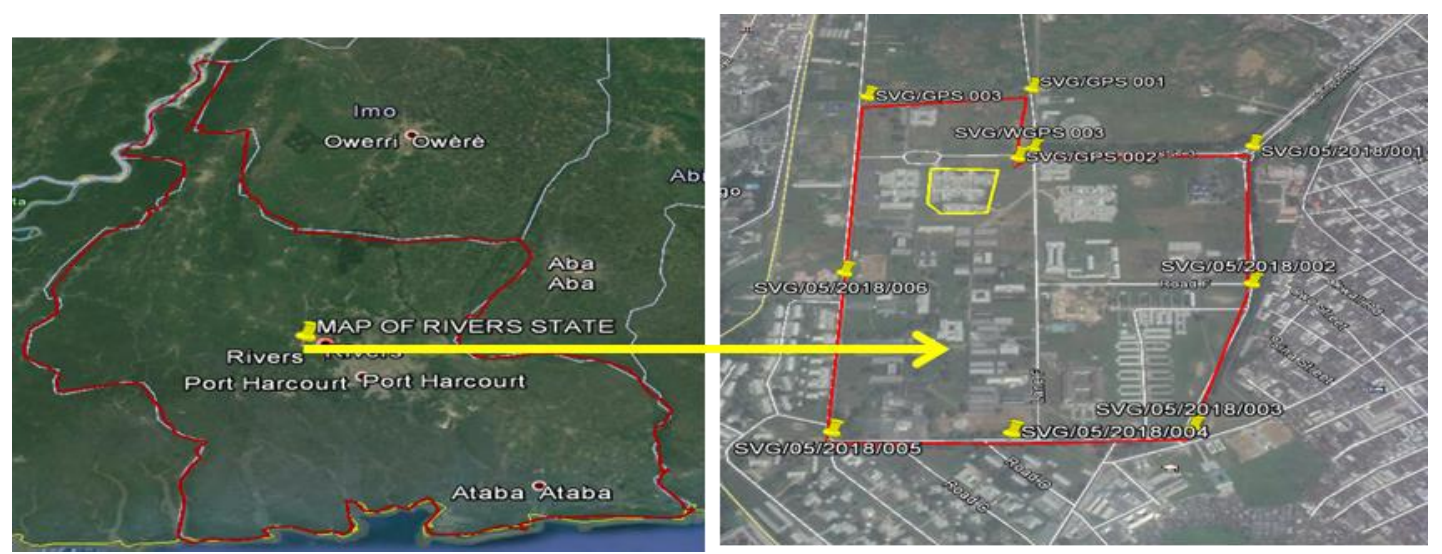

Figure 1: Study Area (Google earth imagery 2018)

\subsection{Methodology}

\subsection{Materials}

This study adopts the quantitative research approach. It relies primarily on the sample observables (data) as shown in Table 1 obtained through field observation in the study area as shown in Figure 1. In other to have the best possible result and to facilitate the computation process, the following 
software were used in the process of carrying out this research, MATLAB version 2018b, Microsoft Excel 2013, AutoCAD 2007 and CASIO fx-7400 GII Programmable Calculator.

Table 1: Traverse Observables (Marcus, 2018)

\begin{tabular}{|l|c|c|l|}
\hline Station from & Distances $(\mathrm{m})$ & Angles $\left({ }^{\circ}{ }^{\prime}\right)$ & Station to \\
\hline WGPS003 & 435.925 & 2240012 & SVG/05/2018/001 \\
\hline SVG/05/2018/001 & 435.389 & 2750805 & SVG/05/2018/002 \\
\hline SVG/05/2018/002 & 413.74 & 1934322 & SVG/05/2018/003 \\
\hline SVG/05/2018/003 & 312.331 & 2494234 & SVG/05/2018/004 \\
\hline SVG/05/2018/004 & 310.411 & 1831148 & SVG/05/2018/005 \\
\hline SVG/05/2018/005 & 439.859 & 2682832 & SVG/05/2018/006 \\
\hline SVG/05/2018/006 & 573.603 & 1820218 & SVG GPS 003 \\
\hline
\end{tabular}

\subsection{Methods}

This research emphasis on the analysis of the various adjustment models to determine their fitness, uniqueness, weakness and strength as it relate to the purpose of positioning and orientation. In order to quantify the effect of any adjustment based on any method, the adjusted observations (distances and angles) are analyzed rather than the plane coordinates computed from those observations, (Ogundare, 2019). The traverse computation and adjustment were done with the aid of Micro Soft Excel 2013, while the method of Least Squares MATLAB was used to facilitate the computational and Adjustment Process as seen in Figure 2 and 3. The steps for quantifying the effect of any adjustment can be given as follows: calculate the coordinates from the field measurements, calculate angles and distances by back-computations using the calculated coordinates and compare the backcomputed quantities with the actual measurements to see how far they deviate from the actual measurements.

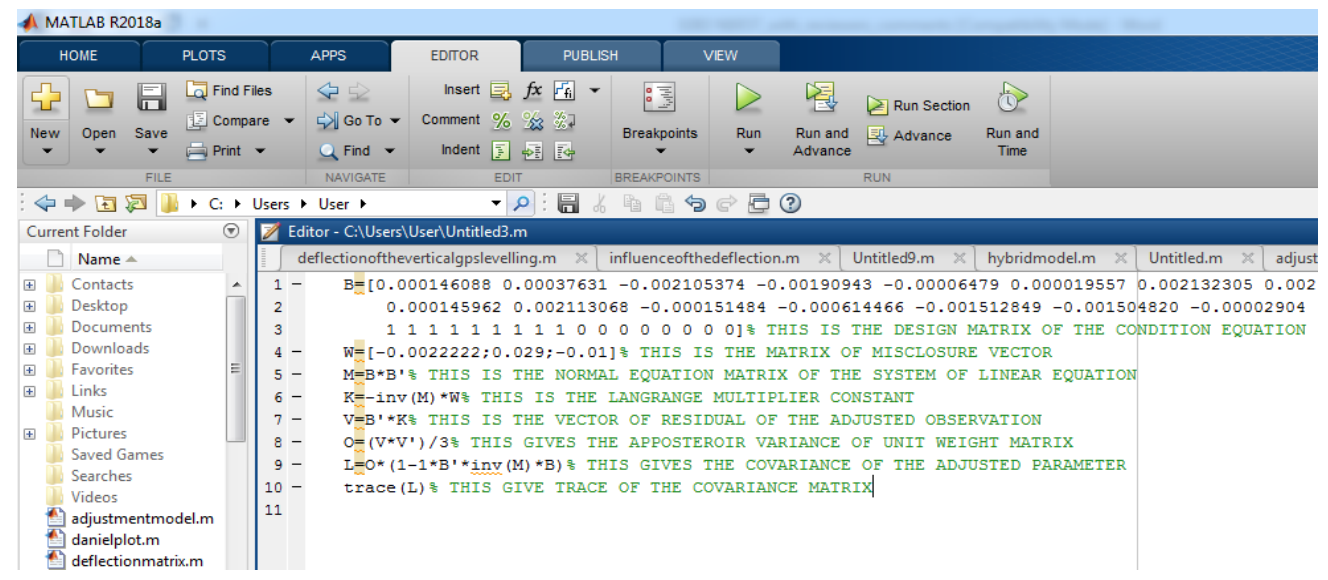

Figure 2: Screenshot of the MATLAB code for the Least Squares Adjustment

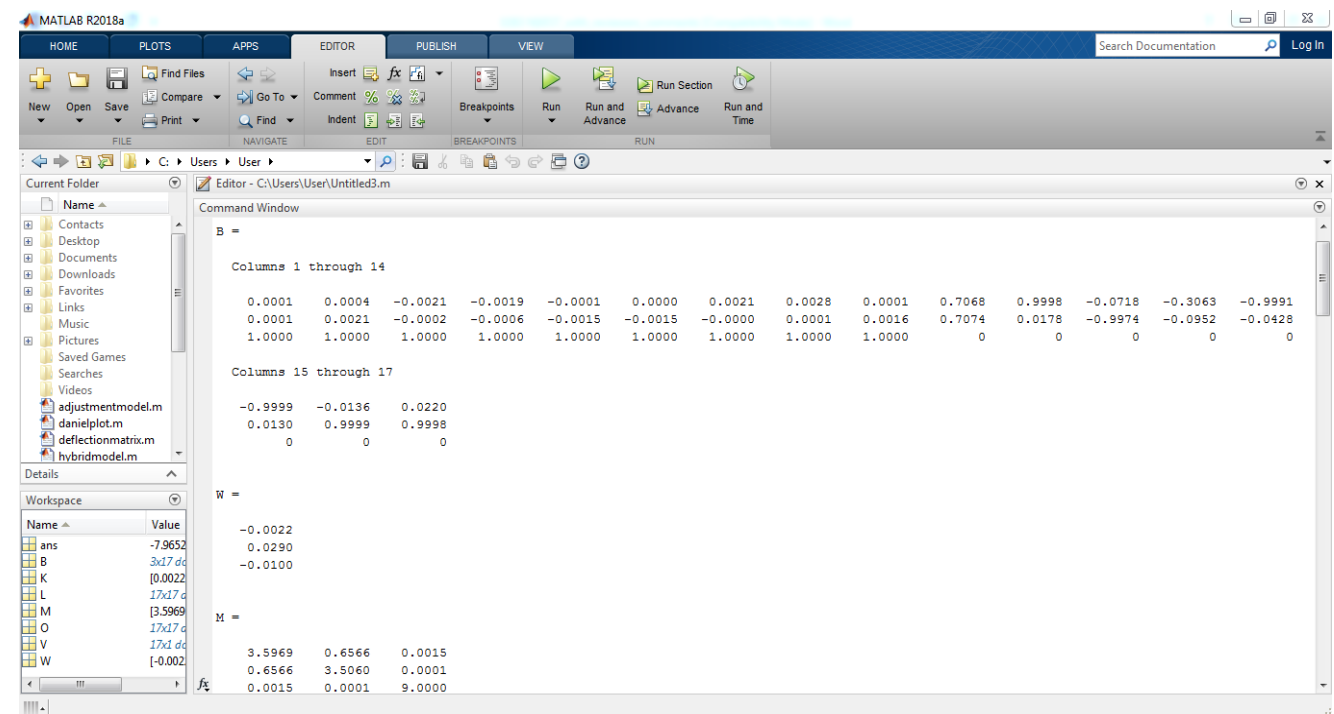

Figure 3: Screenshot of the Derived Parameters for the Condition Equation 


\subsubsection{Traverse adjustment model}

The approximation method of adjustment of traverse network used by geomatics and allied professional includes but not limited to the followings; the transit method, the Bowditch method and the Crandall method. We will critically analyze the models of transit and Bowditch in this work.

\subsubsection{Transit Adjustment Model}

The transit rule method is an empirical method of adjustment that has no theoretical basis. Kimmick (1949) asserts that the displacement of the traverse points is parallel to the error vector and is proportional to the absolute values of the partial northings and eastings. The method assumes the angles measured with transit are more precise than the corresponding distances measured with tape (Duggal, 2008; Ogundare, 2019). The compass rule method, however, determines adjustments or corrections to coordinate changes as follows. For a given total closure error of a traverse in the northing direction as $e_{N}$, the correction ( $C_{\Delta N}$ ) to be applied to the change in northing value $\left(\Delta N_{i}\right)$ for the traverse leg $i$ can be given in Equation 1:

$C_{\Delta N}=-e_{N}\left(\frac{\left|\Delta N_{i}\right|}{\sum_{i}^{n}\left|\Delta N_{i}\right|}\right)$

where $|\Delta \mathrm{Ni}|$ is the absolute value of the change in northing value for the given traverse leg $i$. Similarly, the correction $\left(C_{\Delta E_{i}}\right)$ to be applied to the change in easting value ( $\left.\Delta \mathrm{Ei}\right)$ for the traverse leg $i$ can be given in Equation 2:

$C_{\Delta E}=-e_{E}\left(\frac{\left|\Delta E_{i}\right|}{\sum_{i}^{n}\left|\Delta E_{i}\right|}\right)$

where $|\Delta \mathrm{Ei}|$ is the absolute value of the change in easting value for the given traverse leg $i$. The adjusted coordinate changes for a given traverse leg $i$ are given in Equations 3 and 4:

$$
\begin{aligned}
& \Delta \hat{N}=\Delta N_{i}+C_{\Delta N_{i}} \\
& \Delta N \hat{E}=\Delta E_{i}+C_{\Delta E_{i}}
\end{aligned}
$$

where $\Delta \mathrm{Ni}$ and $\Delta \mathrm{Ei}$ are the adjusted changes in northing and easting values for the given traverse leg $i$. The adjusted coordinates for a given traverse point $k$ are given in Equations 5 and 6 :

$$
\begin{aligned}
& \hat{N}_{k}=\hat{N}_{k-1}+\Delta \hat{N}_{k-1 \longrightarrow k} \\
& \hat{E}_{k}=\hat{E}_{k-1}+\Delta \hat{E}_{k-1 \longrightarrow k}
\end{aligned}
$$

where $\hat{N}_{k}$ and $\hat{E}_{k}$ are the adjusted northing and easting coordinate values, respectively, for the current traverse point k; $\hat{N}_{k-1}$ and $\hat{E}_{k-1}$ are the previously adjusted northing and easting coordinate values, respectively, for the traverse point $k-1$ preceding the current traverse point $\mathrm{k} ; \Delta \hat{N}_{k-1}$ and $\Delta \hat{E}_{k-1}$ are the adjusted changes in northing and easting values for the traverse leg from point $k-1$ to point $k$. 


\subsubsection{Bowditch Adjustment Model}

The Bowditch model underscores the displacement of each point which is parallel to the error vector and proportional to the aggregate of the distances of the locations from the traverse origin, GTM, 1938. The method assumes that the bearing and distance measurements of a traverse leg are uncorrelated. The compass rule method, however, determines adjustments or corrections to coordinate changes as given in Equations 7 and 8 (Jack et al., 2013).

$$
\begin{aligned}
C_{\text {lat }} & =\sum \Delta N \times\left(\frac{L}{D}\right) \\
C_{\text {dep }} & =\sum \Delta E \times\left(\frac{L}{D}\right)
\end{aligned}
$$

where: $C_{\text {lat }}=$ correction of latitude, $C_{\text {dep }}=$ correction of departure, $\sum \Delta E=$ total closure in easting, $\sum \Delta N=$ total closure in northing, $\mathrm{L}=$ cumulative distance of traverse leg, $\mathrm{D}=$ total distance of the traverse.

\subsubsection{Least Squares Adjustment Model}

The least squares is the most rigorous method of adjustment and it yields the unbiased estimates for the parameters which are to be determined. Actually, least squares adjustment is a statistical technique for carrying out objective quality control of measurements by processing set of redundant observations according to mathematically well-defined rules (Leick et al., 2015; Ogundare, 2019). The method of least squares used by spatial analysts for adjustment of traverse includes but not limited to; the method of least squares by observation equation and the method of least squares by condition equation. We can also have the mixed model approach.

\subsubsection{Observation Equation Model}

Observation equations are sets of equations that show the functional relation between observed parameters and the adjusted parameters (Ayeni, 1981). The observation equation method is also known as the parametric least squares model, the method of variation of parameter and also as the Gauss-Markov model (Ogundare, 2019). According to (Uotila, 1978; Vanicek, 1980; Ayeni, 1981; Ghilani and Wolf, 2006; Leick et al., 2015; Ogundare, 2019; Opuaji, 2020), the following mathematical models as given in Equation (9-14) holds true for the observation equation model of least squares adjustment:

$$
\begin{aligned}
& v=A \hat{x}+l \\
& \hat{x}=-\left(A^{T} P A\right)^{-1} A^{T} P l \\
& \sigma_{0}^{2}=\left(\frac{V^{T} P V}{n-m}\right) \\
& \sum \hat{X}=\sigma^{\circ}\left(A^{T} P A\right)^{-1} \\
& L^{a}=L^{b}+V \\
& \sum L^{a}=A \sum \hat{x} A^{T}
\end{aligned}
$$

Equation (9) is the linearized model of the observation equation useful for the determination of the residual of a given observations. Equation (10) is the correction to be applied to the approximate observation to obtain the adjusted parameter. Equation (11) gives the unit weight variance and tell us about the fitness of the adjustment model to the observation (Ayeni, 1981; Opuaji, 2020). It is called the aposterior variance, Equation (12) is the variance covariance matrix, it is fundamentally important because, the diagonal element yield the variance of the adjusted parameter, from which we can determine the standard deviation as a measure of the precision of the observation. From Equation (13) the adjusted observation can be determined and Equation (14) is the covariance matrix of the adjusted observation. Where $A$ is the design matrix or the Jacobian matrix, 1 is the matrix of observations, $v$ is 
the vector of residual, $P$ is the weight matrix, $n$ is the number of observations, $m$ is the number of unknown parameter $(n-m)$ is actually the degree of freedom or redundancy.

\subsubsection{Least Squares Adjustment by Method of Condition Equation}

The condition equation is expressed as a function of the adjusted observation:

$$
\begin{aligned}
& F\left(L^{a}\right)=0 \\
& L^{a}=L^{b}+V \\
& F\left(L^{b}+V\right)=0
\end{aligned}
$$

Linearizing Equation 17 using Taylor's series and truncating at the first order term, gives Equation 18 as shown below:

$$
B \widehat{V}+W=0
$$

Using Lagrange Multiplier $\hat{K}^{T}$ to minimize the sum of the squares of the weighted residuals $\hat{V}^{T} P \hat{V}$, therefore,

$$
\vartheta=\hat{V} P \hat{V}-\hat{K}^{T}(B \hat{V}+W)=\text { minimum }
$$

Differentiating Equation 19 with respect $\hat{V}$ and $\hat{K}^{T}$ to and solving simultaneously yield:

$$
\hat{V}=-P^{-1} B^{T}\left(B P^{-1} B^{T}\right)^{-1} W
$$

It is to be noted that the number of condition equations to be formed must equals the difference between the number of observations and the number of unknown parameters. A detailed derivation on condition equation techniques is given by (Uotila, 1978; Vanicek, 1980; Ayeni, 1981; Leick et al., 2015; Ogundare, 2019; Opuaji, 2020).

\subsubsection{Root Mean Square Error}

A statistical test is one of the ways in checking the degree of internal consistency and reliability of the various adjustment model to give credence to the adjusted observations. The Root Mean Square Error (RMSE) also called the root mean square deviation is a statistical tool used in measuring the difference between the adjusted observations and the observed values (the residual). Equation 21 is the mathematical model for the determination of the root mean square error as given by (Uotila, 1967; Vanicek, 1980; Ayeni, 1981; Ghilani and Wolf, 2006; Alsadik, 2019; Oba et al., 2020):

$$
R M S E=\sqrt{\left(\frac{\sum_{i=1}^{n}(x-\bar{x})^{2}}{n-1}\right)}
$$

\subsection{Results and Discussion}

From Table 2, the linear misclosure in eastings is 0.00514 meters and northings as 0.013485 meters. The perimeter of the traverse network is 2,921.258 meters (2.921258 kilometers). Similarly, from Tables 3 and 4 showed that the variation in the values of the adjusted coordinates obtained from the Bowditch and transit approximation methods of traverse adjustment are in sub meters value. The impact of these variations may not be significant in small locations as was the case of this study, however, their inherent attributes was contributory to the variations. In another vein, Tables 5 and 6 describes the scale and azimuth variation between computed and observed values. The Bowditch model showed high values in azimuth 19.49 and 22.43 seconds as against 3.08 and 6.01 seconds 
respectively using the transit model on the same stations. There was no significant variation in the distances as applicable to both models. This notwithstanding, Tables 7 and 8 showed the values of the magnitude of the residuals in terms of the distances and angles as compared with the residual values of the condition equation method of least square adjustment model. Further to these, the graphical representations of the computed residuals for distances and angles are given Figures 4 and 5 it can be clearly seen that the Bowditch adjustment models yield the highest residual with a Root Mean Squares of 0.128702264 . This is because this method of adjustment only takes into consideration linear measurement in the adjustment process. The maximum values of angular residuals as indicated at stations SVG/05/2018/003 and SVG/05/2018/004 respectively. The residuals of both methods are significantly convergent at station SVG/05/2018/005 and 006. Conversely, the Bowditch model revealed a significant variation in the residuals of the distances as against the transit model that showed correlation with the values of the least square adjustment model. However, the propagation of error to the unknown parameter (coordinates) is a function of both the distances and the directions. Since error in angular measurement increases over long distances, the Bowditch method is therefore not suitable for the adjustment of traverse network of large areas. Although, the transit adjustment models take into considerations both the linear and directional measurement during the adjustment process, its weakness lies in the fact that it makes no provision for assigning appropriate weight to the observations in the adjustment processes. Hence the degree of precision in which the measurement where captured is irrelevant in the adjustment process. The result of the Root Means Squared Error (RMSE) of the various models is given as $0.128702264,0.008560954$, and 0.005763969 for the Bowditch model, transit model, and condition equation model respectively.

Table 2: Result of the Provisional Coordinates before Adjustment

\begin{tabular}{|l|l|l|l|l|l|l|l|}
\hline Station from & $\begin{array}{l}\text { Distances } \\
(\mathrm{m})\end{array}$ & Bearings & $\begin{array}{l}\text { Delta } \\
\text { Northing }\end{array}$ & $\begin{array}{l}\text { Delta Easting } \\
\text { Uasting }(\mathrm{m})\end{array}$ & $\begin{array}{l}\text { Unadjusted } \\
\text { Northings }(\mathrm{m})\end{array}$ & Station to \\
\hline WGP003 & & & $\Delta \mathrm{N}(\mathrm{m})$ & $\Delta \mathrm{E}(\mathrm{m})$ & 275992.841 & 530933.315 & WGPS003 \\
\hline SVG/05/2018/001 & 435.925 & 88.977026 & 7.782727 & 435.85552 & 276428.69652 & 530941.0977 & SVG/05/2018/001 \\
\hline SVG/05/2018/002 & 413.740 & 194.11323 & -434.268 & -31.22943 & 276397.46709 & 530506.8302 & SVG/05/2018/002 \\
\hline SVG/05/2018/003 & 312.331 & 267.54793 & -13.3627 & -312.04502 & 275958.68576 & 530099.6164 & SVG/05/2018/004 \\
\hline SVG/05/2018/004 & 310.411 & 270.74295 & 4.024902 & -310.38490 & 275648.30086 & 530103.6413 & SVG/05/2018/005 \\
\hline SVG/05/2018/005 & 439.859 & 359.22012 & 439.8183 & -5.98700 & 275642.31386 & 530543.4595 & SVG/05/2018/006 \\
\hline SVG/05/2018/006 & 573.603 & 1.2568856 & 573.465 & 12.58200 & 275654.89586 & 531116.9245 & SVG GPS 003 \\
\hline & & & & & 275654.90100 & 531116.9380 & \\
\hline & $2,921.258$ & & & MISCLOSURE & 0.00514 & 0.013485474 & \\
\hline
\end{tabular}

Table 3: Adjustment of the Traverse Network using the Bowditch Method

\begin{tabular}{|l|r|l|l|l|l|l|l|}
\hline & $\begin{array}{l}\text { Horizontal } \\
\text { Distance } \\
(\mathrm{m})\end{array}$ & $\begin{array}{l}\text { Corrected } \\
\text { Bearings }\end{array}$ & $\begin{array}{l}\text { Corrected } \\
\text { Delta } \\
\text { Northings }\end{array}$ & $\begin{array}{l}\text { Corrected } \\
\text { Delta } \\
\text { Eastings }\end{array}$ & $\begin{array}{l}\text { Adjusted } \\
\text { Eastings }(\mathrm{m})\end{array}$ & $\begin{array}{l}\text { Adjusted } \\
\text { Northings (m) }\end{array}$ & Station to \\
\hline & & & $\Delta \mathrm{N}(\mathrm{m})$ & $\Delta \mathrm{E}(\mathrm{m})$ & 275992.8410 & 530933.3150 & WGPS003 \\
\hline WGPS003 & 435.925 & 88.977026 & 7.78349 & 435.8575329 & 276428.6985 & 530941.0985 & SVG/05/2018/001 \\
\hline SVG/05/2018/001 & 435.389 & 184.11323 & -434.26602 & -31.22540709 & 276397.4731 & 530506.8325 & SVG/05/2018/002 \\
\hline SVG/05/2018/002 & 413.74 & 197.83753 & -393.84885 & -126.7303787 & 276270.7427 & 530112.9836 & SVG/05/2018/003 \\
\hline SVG/05/2018/003 & 312.331 & 267.54793 & -13.35989 & -312.0376415 & 275958.7051 & 530099.6237 & SVG/05/2018/004 \\
\hline SVG/05/2018/004 & 310.411 & 270.74295 & 4.02826 & -310.3760976 & 275648.3290 & 530103.6520 & SVG/05/2018/005 \\
\hline SVG/05/2018/005 & 439.859 & 359.22012 & 439.82238 & -5.976165 & 275642.3528 & 530543.4744 & SVG/05/2018/006 \\
\hline SVG/05/2018/006 & 573.603 & 1.2568856 & 573.47013 & 12.59548543 & 275654.9483 & 531116.9445 & SVG GPS 003 \\
\hline
\end{tabular}

Table 4: Adjustment of the Traverse Network using the Transit Method

\begin{tabular}{|l|c|l|l|c|l|l|l|}
\hline & $\begin{array}{l}\text { Correction } \\
\text { for Delta } \\
\text { Northings }\end{array}$ & $\begin{array}{l}\text { Correction } \\
\text { for Delta } \\
\text { Eastings }\end{array}$ & $\begin{array}{l}\text { Corrected } \\
\text { Delta } \\
\text { Northings }\end{array}$ & $\begin{array}{l}\text { Corrected } \\
\text { Delta } \\
\text { Eastings }\end{array}$ & $\begin{array}{l}\text { Adjusted } \\
\text { Eastings (m) }\end{array}$ & $\begin{array}{l}\text { Adjusted } \\
\text { Northings (m) }\end{array}$ & Station to \\
\hline & & & $\Delta \mathrm{N}(\mathrm{m})$ & $\Delta \mathrm{E}(\mathrm{m})$ & 275992.84100 & 530933.3150 & WGPS003 \\
\hline WGPS003 & 0.01349 & 0.00514 & 7.79621 & 435.86066 & 276428.70166 & 530941.11121 & SVG/05/2018/001 \\
\hline SVG/05/2018/001 & 0.01325 & 0.0003437 & -434.25430 & -31.22909 & 276397.47257 & 530506.85691 & $\mathrm{SVG} / 05 / 2018 / 002$ \\
\hline $\mathrm{SVG} / 05 / 2018 / 002$ & 0.00635 & 0.001097 & -393.84475 & -126.73521 & 276270.73736 & 530113.01216 & $\mathrm{SVG} / 05 / 2018 / 003$ \\
\hline $\mathrm{SVG} / 05 / 2018 / 003$ & 0.00021 & 0.0017706 & -13.36249 & -312.04325 & 275958.69412 & 530099.64967 & $\mathrm{SVG} / 05 / 2018 / 004$ \\
\hline SVG/05/2018/004 & $6.4 \mathrm{E}-05$ & 0.0013117 & 4.02497 & -310.38359 & 275648.31052 & 530103.67463 & $\mathrm{SVG} / 05 / 2018 / 005$ \\
\hline SVG/05/2018/005 & 0.00459 & $2.518 \mathrm{E}-05$ & 439.82284 & -5.98698 & 275642.32355 & 530543.49747 & $\mathrm{SVG} / 05 / 2018 / 006$ \\
\hline SVG/05/2018/006 & 0.00414 & $5.237 \mathrm{E}-05$ & 573.46913 & 12.58205 & 275654.90560 & 531116.96661 & $\mathrm{SVG} \mathrm{GPS} \mathrm{003}$ \\
\hline
\end{tabular}


Table 5: Differences between Observed and Adjusted Distances and Angles after Adjustment using Bowditch Method

\begin{tabular}{|c|c|c|c|c|c|c|c|}
\hline $\begin{array}{l}\text { Point ID } \\
\text { (From) }\end{array}$ & $\begin{array}{c}\text { Observed } \\
\text { distances } \\
\text { (m) }\end{array}$ & $\begin{array}{l}\text { Adjusted } \\
\text { Distances } \\
\text { (m) }\end{array}$ & $\begin{array}{l}\text { Difference } \\
\quad(\mathrm{m})\end{array}$ & $\begin{array}{c}\text { Observed } \\
\text { Angles } \\
\left({ }^{0} \cdot{ }^{\prime}\right)\end{array}$ & $\begin{array}{c}\text { Adjusted } \\
\text { Angles } \\
\left.\left({ }^{0} ، '\right)\right)\end{array}$ & $\begin{array}{l}\text { Diff. } \\
\left.\left({ }^{0} ، \cdot\right)^{\prime}\right)\end{array}$ & $\begin{array}{l}\text { Point ID } \\
\text { (To) }\end{array}$ \\
\hline WGPS 003 & 435.925 & 435.92703 & 0.00203 & 2240012 & & & SVG/05/2018/001 \\
\hline SVG/05/2018/001 & 435.389 & 435.38719 & -0.00181 & 2750805 & 2750817.29 & 0012.29 & SVG/05/2018/002 \\
\hline SVG/05/2018/002 & 413.74 & 413.73603 & -0.00397 & 1934322 & 1934327.62 & 0005.62 & SVG/05/2018/003 \\
\hline SVG/05/2018/003 & 312.331 & 312.32351 & -0.00749 & 2494234 & 2494253.49 & 0019.49 & SVG/05/2018/004 \\
\hline SVG/05/2018/004 & 310.411 & 310.40224 & -0.00876 & 1831148 & 1831125.57 & -0022.43 & SVG/05/2018/005 \\
\hline SVG/05/2018/005 & 439.859 & 439.86298 & 0.00398 & 2682832 & 2682835.58 & 003.58 & SVG/05/2018/006 \\
\hline SVG/05/2018/006 & 573.603 & 573.60843 & 0.00543 & 1820218 & 1820214.59 & -0003.41 & SVG GPS 003 \\
\hline
\end{tabular}

Table 6: Differences between Observed and Adjusted Distances and Angles after Least Squares Adjustment using Transit method

\begin{tabular}{|c|c|c|c|c|c|c|c|}
\hline $\begin{array}{l}\text { Point ID } \\
\text { (From) }\end{array}$ & $\begin{array}{l}\text { Observed } \\
\text { distances } \\
\text { (m) }\end{array}$ & $\begin{array}{c}\text { Adjusted } \\
\text { Distances } \\
\quad(\mathrm{m})\end{array}$ & Diff.(m) & $\begin{array}{c}\text { Observed } \\
\text { Angles } \\
\left({ }^{0} \cdot ،\right)\end{array}$ & $\begin{array}{c}\text { Adjusted } \\
\text { Angles } \\
\left({ }^{0} \cdot c\right)\end{array}$ & $\begin{array}{c}\text { Difference } \\
(0 ،, ")\end{array}$ & $\begin{array}{l}\text { Point ID } \\
\text { (To) }\end{array}$ \\
\hline WGPS 003 & 435.925 & 435.93038 & 0.0054 & 2240012 & & & SVG/05/2018/001 \\
\hline SVG/05/2018/001 & 435.389 & 435.37576 & -0.0132 & 2750805 & 2750816.95 & 0011.95 & SVG/05/2018/002 \\
\hline SVG/05/2018/002 & 413.74 & 413.73362 & -0.0064 & 1934322 & 1934327.62 & 005.62 & SVG/05/2018/003 \\
\hline SVG/05/2018/003 & 312.331 & 312.32922 & -0.0018 & 2494234 & 2494237.08 & 003.08 & SVG/05/2018/004 \\
\hline SVG/05/2018/004 & 310.411 & 310.40969 & -0.0013 & 1831148 & 1831141.99 & 006.01 & SVG/05/2018/005 \\
\hline SVG/05/2018/005 & 439.859 & 439.86359 & 0.0046 & 2682832 & 2682837.89 & 005.89 & SVG/05/2018/006 \\
\hline SVG/05/2018/006 & 573.603 & 573.60714 & 0.0041 & 1820218 & 1820212.27 & -005.73 & SVG GPS 003 \\
\hline
\end{tabular}

Table 7: Result showing the Computed Distances Residuals for the Two-Adjustment Methods against the Least Square Method

\begin{tabular}{|l|l|l|l|l|}
\hline Station From & Transit Method & Bowditch Method & Condition Equation Method & Station To \\
\hline WGPS001 & 0.0054 & 0.1185 & 0.005 & SVG/05/2018/001 \\
\hline SVG/05/2018/001 & -0.0132 & 0.0305 & 0.006 & SVG/05/2018/002 \\
\hline SVG/05/2018/002 & -0.0064 & 0.2592 & 0.004 & SVG/05/2018/003 \\
\hline SVG/05/2018/003 & -0.0018 & -0.0993 & -0.005 & SVG/05/2018/004 \\
\hline SVG/05/2018/004 & -0.0013 & -0.0845 & -0.005 & SVG/05/2018/005 \\
\hline SVG/05/2018/005 & 0.0046 & -0.0037 & -0.006 & SVG/05/2018/006 \\
\hline SVG/05/2018/006 & 0.0041 & 0.0114 & -0.006 & SVG GPS 003 \\
\hline
\end{tabular}

Table 8: Angular Residuals in Decimal of Degree for the Various Adjustment Methods

\begin{tabular}{|l|l|l|l|}
\hline Stations & Bowditch Method & Transit Method & LSA condition equation \\
\hline SVG/05/2018/001 & 0.003412500 & 0.003318333 & 0.0003 \\
\hline SVG/05/2018/002 & 0.001562222 & 0.001561389 & 0.0003 \\
\hline SVG/05/2018/003 & 0.005414722 & 0.000855556 & 0.0002 \\
\hline SVG/05/2018/004 & -0.006230000 & -0.001670000 & 0.0002 \\
\hline SVG/05/2018/005 & 0.000994444 & 0.001636111 & 0.0002 \\
\hline SVG/05/2018/006 & -0.000948333 & -0.001590833 & 0.0002 \\
\hline TOTAL & 0.004205555 & 0.004110555 & 0.0014 \\
\hline
\end{tabular}




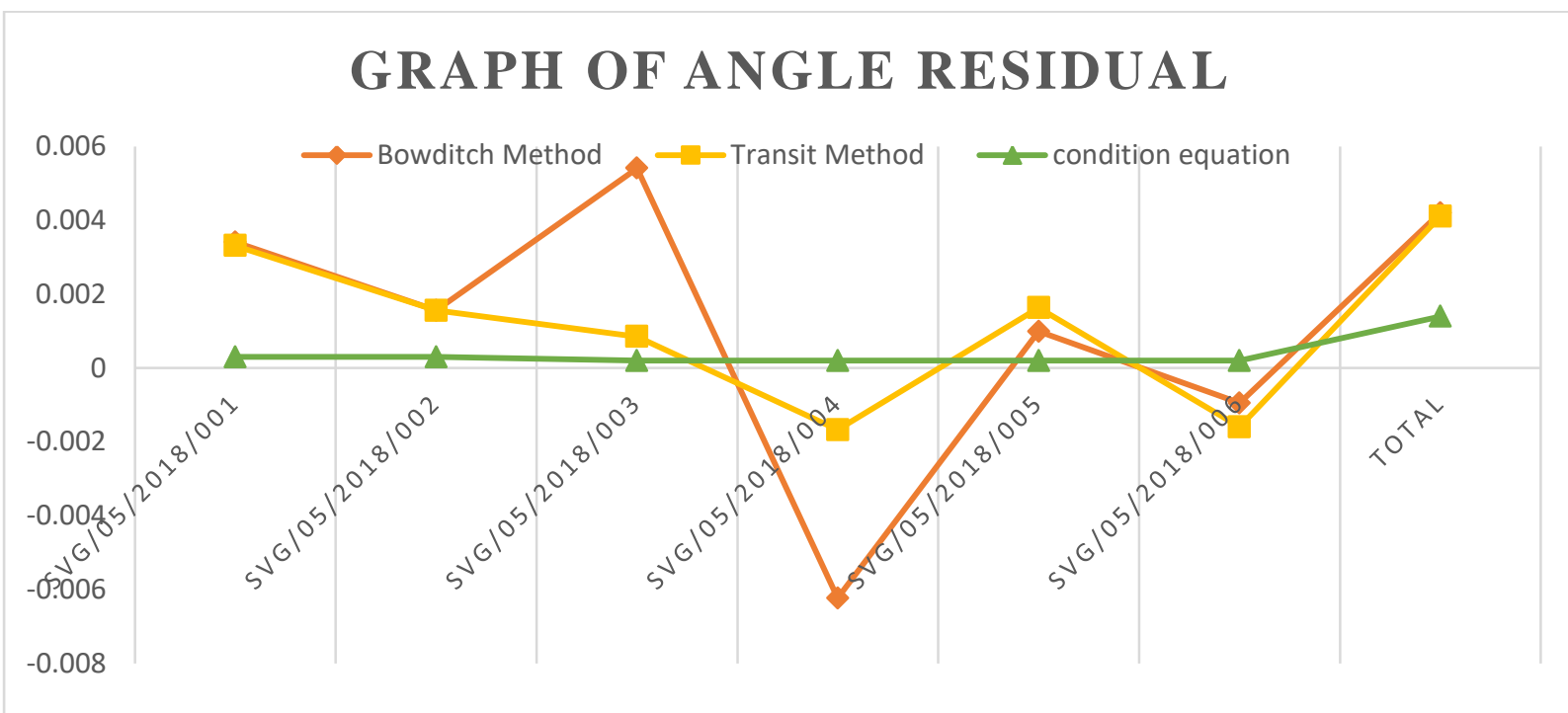

Figure 4: Showing plot of distance residual for the three adjustment methods

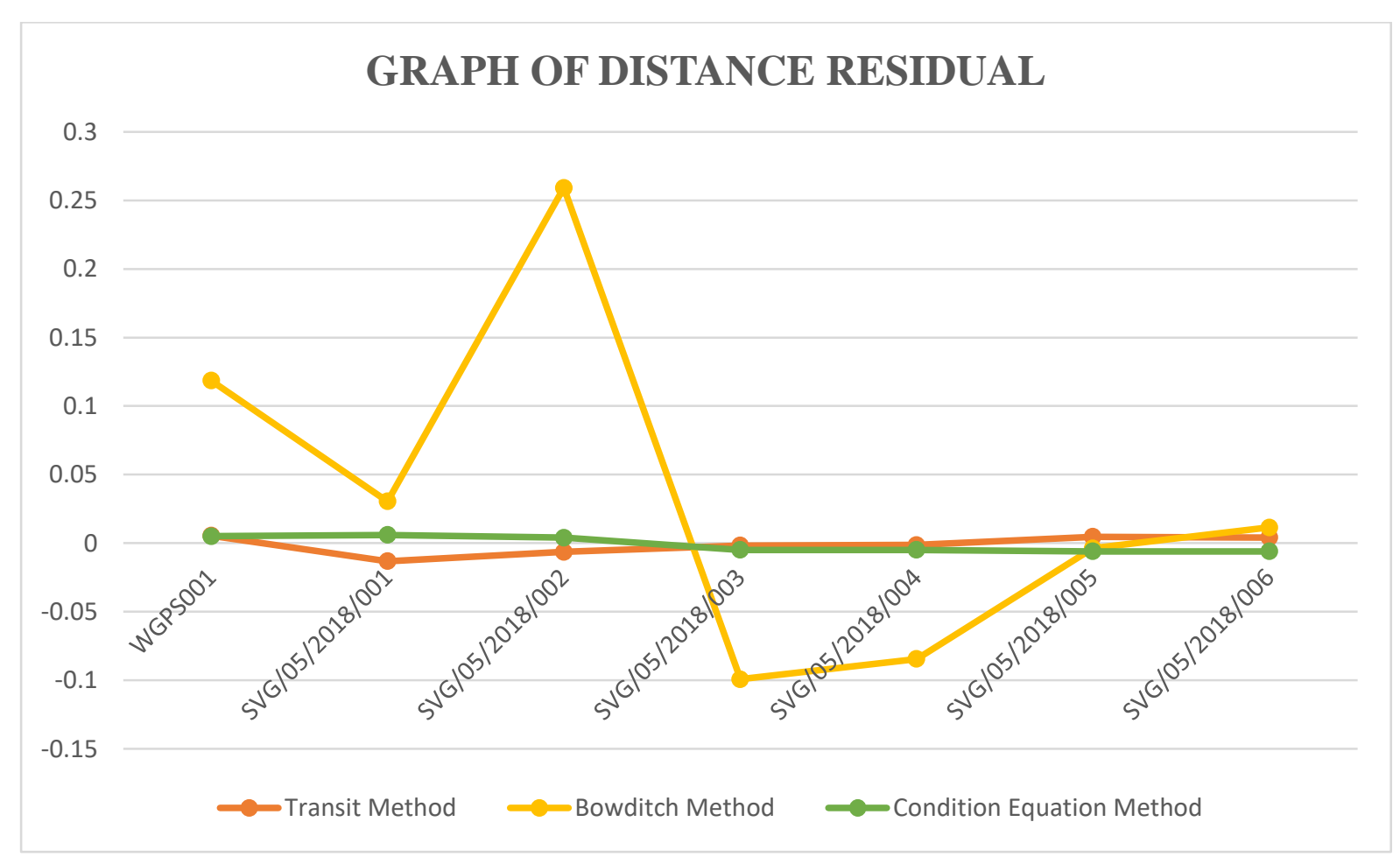

Figure 5: Plot of distance residual for the three adjustment methods

\subsection{Conclusion}

In our quest to properly map the earth or near-earth surfaces particularly using classical approach of data acquisition, which requires the measurement of distances and determination of angles of various accuracies this will underscore the choice of adjustment model. Therefore, any adjustment model adopted will seek to propagate the magnitude of the errors of the observations on the traverse stations irrespective of the method and facilities deployed. This means that the surveyor who purchases an accurate surveying instrument will have to ignore the accuracy achieved with such an instrument when adjusting the measurements acquired with the instrument, which will be unreasonable. However, these traverse adjustment models are considered fit for less precise surveys involving small areas. The condition equation model is unique in that it gives the minimum residual in angles. This can be attributed to the fact that outside making provision for appropriate weighting of the observations, condition equations also take into consideration the geometry properties of the network. 


\section{References}

Ayeni, O. O. (1981). Statistical Adjustment and Analysis of Data: (with applications in geodetic surveying and photogrammetry, A Manual, in the Department of Surveying \& Geoinformatics, Faculty of Engineering, University of Lagos, Nigeria.

Alsadik, B. (2019). Adjustment Models in 3D Geomatics and computational Geophyics with MATLAB examples. Elsevier Inc., Radarweg 29, PO BOX 211, 1000 AE Amsterdam, Netherlands. ISBN: 978-0-12-817588-8.

Duggal, S. K. (2008) Surveying Volume I. $2^{\text {nd }}$ Edition. Tata McGraw-Hill Publishing Company Limited. New Delhi. ISBN: 13-978-0-07-053470-4.

El-Rabbany, A. (2002). Introduction to GPS: The Global Positioning System. Artech House. Inc., 685 Canton Street, Norwood, MA 02062. ISBN: 1-58053-183-0.

Fajimirokun, F. A. (2012). Ed. Contemporary Issues in Surveying and Geoinformatics. Published by BPrint, 51, Remi-Fani Kayode Avenue, off Oduduwa Street, GRA Ikeja Lagos, Nigeria. ISBN:978915-670-2.

Fubara, M. J., Fajimirokun, F. A. and Ezeigbo, (2014). Fundamental of Geodesy. Concept Publication Limited. 77, Shipeolu Street, Palmgrove, Lagos, Nigeria. ISBN: 978-987-525562-1-5.

Ghilani, C. D. and Wolf, P. R. (2006). Adjustment Computations; Spatial Data Analysis. John Wiley $\&$ Sons, Inc, Hoboken, New Jersey, $4^{\text {th }}$ ed. ISBN-13-978-0-471-69728-2.

Ghilani, C. D. and Wolf, P. R. (2016). Elementary Surveying; an introduction to Geomatics. Pearson Education, Inc, Upper Saddle River, New Jersey, $13^{\text {th }}$ ed. ISBN-13:978-0-13-255434-5.

GTM, 1938. Bowditch Traverse Adjustment and a Modification. Empire Survey Review, 4(29), pp 417-425.

Hart, L., Opuaji, A. and Basil, D. (2016). Error Analysis a Tools for Quality Control in Cadastral Practice in Nigeria. A Conference Paper Presented at the Annual General Meeting of the Nigerian Institution of Surveyor, Bayelsa State, Nigeria.

Hart, L., Marcus, H. and Oba, T. (2020). Providing Geodetic Infrastructure; Imperative of the Classical Approach in Small Locations. Nigerian Journal of Geodesy, 3(2) pp. 81-87, ISSN 26516098.

Hofmann-Wellenhof, B., Lichtenegger, H. and Wasle, E. (2008). GNSS-Global Navigation Satellite Systems (GPS, Glonass, Galileo and More); Springer: Wien, NY, USA.

Jack M, Wayne S., \& Williams D. (2013). Surveying. $6^{\text {th }}$ Ed. John Wiley \& Sons, Inc. 222 Rosewood Drive, Danvers, MA01923. ISBN: 978-0-470-49661-9.

Kimmick, E. J. (1949). Analysis of the transit traverse survey method of the United States Department of Interior, Geological Survey.

Leick, A., Rapoport, L. and Tarniko, D. (2015). GPS Satellite Surveying. Fourth Edition. John Wiley \& Sons, Inc., Hoboken, New Jersey. ISBN: 978-1-118-67557-1.

Marcus, H. (2018). Establishment of Geodetic Control Network in River State University Campus. An Unpublished Project Work Submitted to the Department of Surveying and Geomatics, Rivers State University, Nkpolu-Oroworoko, Port Harcourt.

Oba, T., Hart, L. and Moka, E. C. (2020). Local Geospatial Geoid Determination for Rivers State, Nigeria. IOSR Journal of Engineering (IOSRJEN), 10(1), pp. 59-67. 
Ogundare (2019). Understanding Least Squares Estimation and Geomatics Data Analysis. John Wiley \& Sons, Inc., 111 Rivers Street, Hoboken, NJ 07030, USA. ISBN:9781119501442

Opuaji, T. A. (2020). Unpublished Lecture Note on Advanced Geomatics Computation and Adjustment. Department of Surveying and Geomatics, Rivers State University, Nkpolu Orowuoroko, Port Harcourt.

Uotila, U. A. (1967) Introduction to Adjustment Computations with Matrices; Lecture notes (unpublished), Geodetic Science Department, the Ohio State University.

Vanicek, P. (1980). Introduction to Adjustment Calculus. Unpublished Lecture Note 35, Department of Geodesy and Geomatics Engineering, University of New Brunswick, P.O.BOX 444 Frederiction, N. B. Canada EBB5A3

Vanicek, P. and Krakiwsky, E. J. (1986). Geodesy; the concept. Elsevier Science Publishers B. V., P.O. BOX 1991, 1000 BZ Amsterdam the Netherland. Second Edition. ISBN: 044877754.

\section{Cite this article as:}

Hart L., Basil D. D. and Oba T., 2021. Assessment of Adjustments Methods in Traverse Networks for Positioning. Nigerian Journal of Environmental Sciences and Technology, 5(2), pp. 354-364. https://doi.org/10.36263/nijest.2021.02.0283 